\title{
Tungaloy Ceramic Cutting Tools at INTERRUPTED MACHINING
}

\author{
CEP, R.; JANASEK, A. \& PETRU, J.
}

Abstract: The paper deals with testing of ceramic cutting tools with an interrupted machining. Tests will be provided on fixture - interrupted cut simulator. This simulator has four mouldings on circumference and cutting edge gets shocks during one revolution. Criterion of tool wear is destruction of cutting tool or 6000 shocks. As testing cutting tool material will be ceramic cutting tools of Tungaloy Company. Machined materials were steels 15128 (13MoCrV6) and 12050 (C45). Cutting speeds and cutting feeds were variable parameters and cutting depth was a constant parameter.

Key words: machining, interrupted cut, tool-life tests, ceramic cutting tool, longitudinal turning
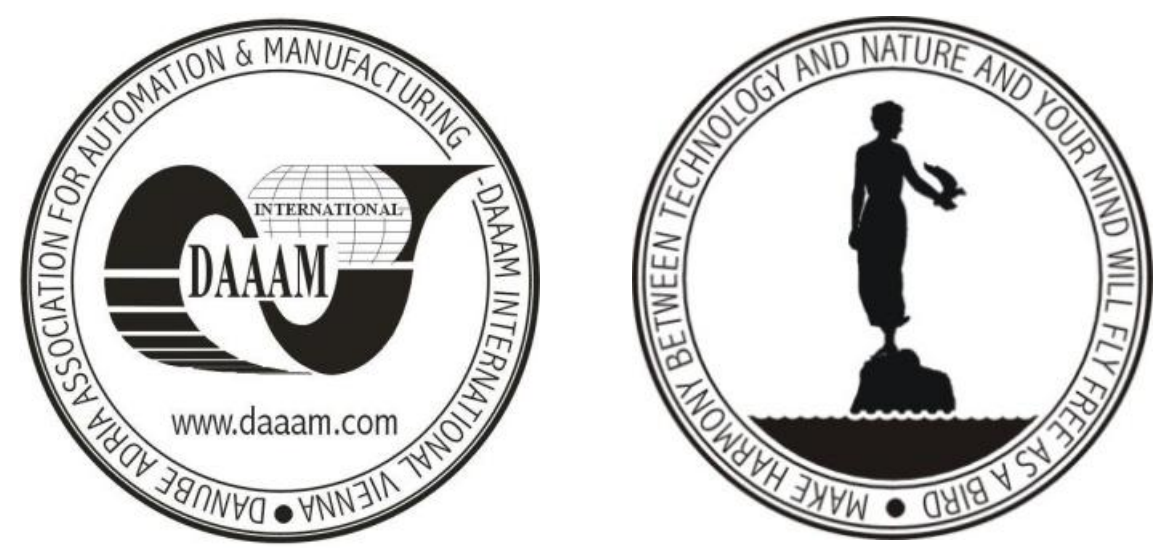

Authors' data: Assoc. Prof., Ph.D., MSc. Cep, R[obert]; MSc. Janasek, A[dam]; multi MSc., M. A., Ph.D. Petru, J[ana], 346 - Department of Machining and Assembly, Faculty of Mechanical Engineering, VŠB - Technical University of Ostrava, 17. listopadu 15/2172, 70833 Ostrava - Poruba, Czech Republic, robert.cep@vsb.cz, adam.janasek@vsb.cz,jana.petru@vsb.cz

This Publication has to be referred as: Cep, R[obert]; Janasek, A[dam] \& Petru, J[ana] (2012). Tungaloy Ceramic Cutting Tools at Interrupted Machining, Chapter 35 in DAAAM International Scientific Book 2012, pp. 401-412, B. Katalinic (Ed.), Published by DAAAM International, ISBN 978-3-901509-86-5, ISSN 1726-9687, Vienna, Austria

DOI: 10.2507/daaam.scibook.2012.35 
Cep, R.; Janasek, A. \& Petru, J.: Tungaloy Ceramic Cutting Tools at Interrupted M...

\section{Introduction - The Methodology of Cutting Tool Testing}

Turning tests are focused on machining by smooth cut at constant or variable depth of cut (Dobransky \& Hatala, 2007), (Cep et al., 2008), (Jurko et al., 2009). In this work we will use one of the developed tests. It is longitudinal turning, so-called "slat test" (Cep, 2010). Experiments were conducted on a special preparation which was constructed at Department of Machining and Assembly, VŠB - Technical University of Ostrava (see Fig. 1.).

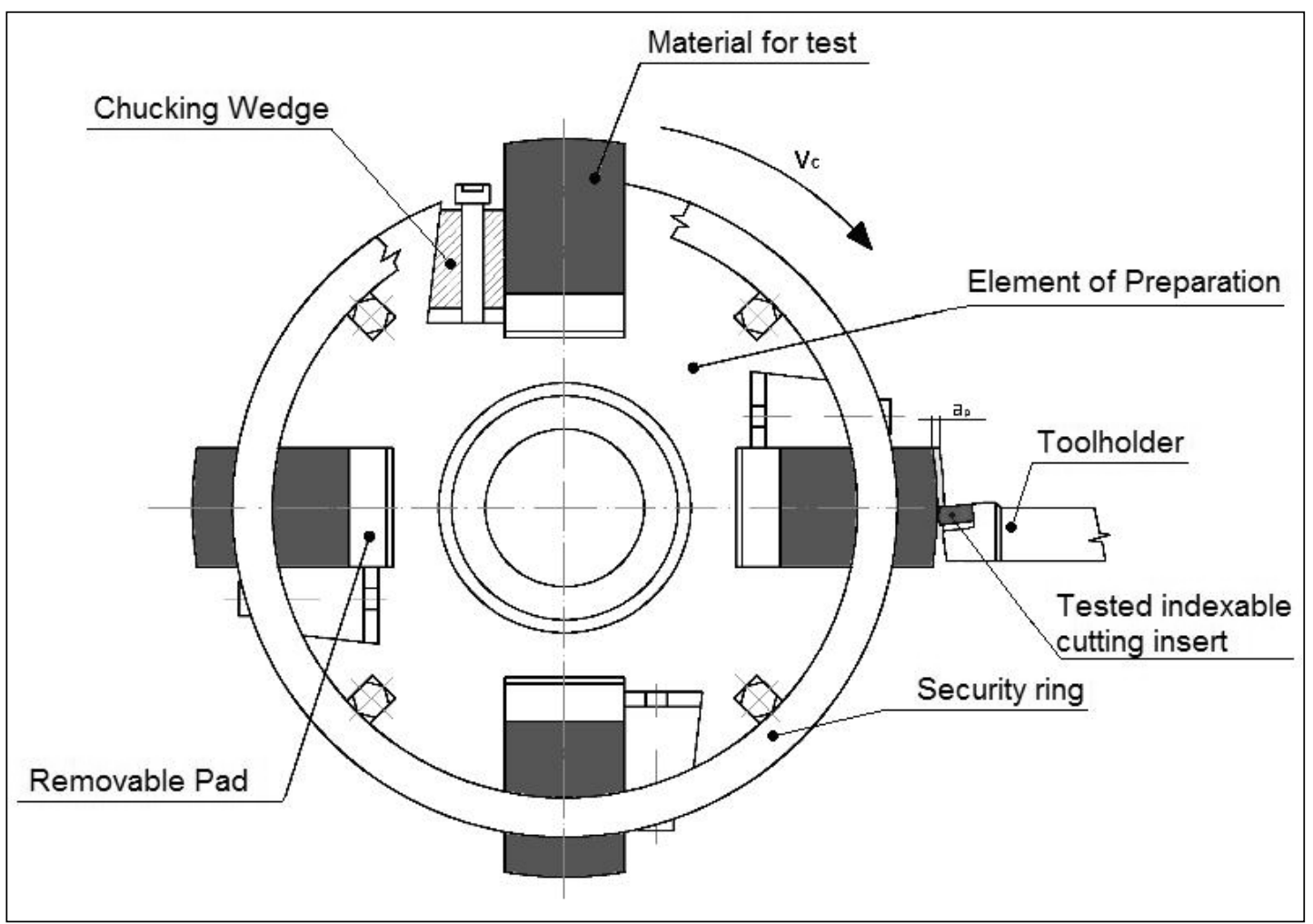

Fig. 1. Scheme of preparation (Reiner, 2009)

A preparation in the shape of a cylinder consists of four exchangeable slats which are clamped in the grooves by the chucking wedge. The basic construction consists of special cylinders which are milled four mortises (measurement: 70 x 48 $\mathrm{mm}$ in $600 \mathrm{~mm}$ length). Slats can be put under by washers so we can provide the stable cutting diameter. Edge of cutting insert is exposed to four shocks during one revolution. The product is also equipped with circlips. If we want to guarantee a constant depth of chips and we want to avoid of vibration it is necessary to cut off the first depth of chips before measurements.

The limitation is created by prepared construction that can not be clamped with differently wide slats and can not change the ratio between the time mesh and the duration of edge cooling in the gap.

The ceramic cutting tools for testing were supplied by Tungaloy Company. We tested two types of ceramic indexable cutting inserts. These cutting inserts have a standard shape SNGN 120716 and used materials were FX105 and CX710 (Tungaloy Catalogue, 2007). 
We have choosen steels 15128 (13MoCrV6) and 12050 (C45) as workpiece materials. Carbon steel $\mathrm{C} 45$ was chosen on the basis that it is a reference material for the class of machinability 14b. Its hardness ranges is 180-220 HB. The second material was chosen for its mechanical properties, especially higher toughness. This material was chosen for "sharpening" of tests. Ceramic cutting tools are usable especially for cast iron machining. For this reason steel was chosen in order to rebut the presumption rooted that is suitable for cutting ceramics for machining cast iron and not suitable for interrupted cutting.

Firstly, the preparation should be clamped to the turning lathe. It is fastened to the turning lathe chuck and buttresses with the tip established in tailstock sleeve. Slats are gradually put in the preparation, that are clamped by wedge-shaped jaws. If we want to guarantee a constant depth and we want to avoid of vibration it is necessary to cut off the first depth of chips before we start taking the measurements.

\section{Cutting Parameters, Cutting Geometry and Machine Tool}

We choose these parameters with regard to manufacturer's recommendation of cutting ceramics and experience of the resolvers. The following cutting conditions were chosen for testing these types of cutting materials:

- Cutting speeds $\mathrm{v}_{\mathrm{c}}=(408 ; 580) \mathrm{m} / \mathrm{min}$,

- Feeds $\mathrm{f}=(0,15 ; 0,20 ; 0,25 ; 0,30) \mathrm{mm}$,

- Cutting depth $\mathrm{a}_{\mathrm{p}}=1 \mathrm{~mm}$.

Cutting geometry for tool testing from cutting ceramics was chosen with regard to ISO 3685 standard - Tool Life Testing of Single Point Turning Tools (ISO 3685, 1990). All types of indexable cutting inserts, that we will be tested, have a normalize shape SNGN 120716 T02020 and will be attached to the tool holder CSRNR 25x25 M12-K.

Ceramics have intrinsic characteristics such as high melting point, high hardness, good chemical inertness and high wear resistance, which make them, a promising contender for high - temperature structural and wear resistance components (Amin, 2011).

Tests were conducted on the turning lathe ZMM SLIVEN. This lathe has a rigid structure that allows rigid clamping and absorbs shocks very well and reaches mostly 2000 RPM. This turning-lathe is conveniented for this type of experiments.

\section{Monitoring Number of Shocks}

The main criterion of tool wear was a tool-fracture at measurement. This moment was noticed by changing the cutting sound, sparking or worsen in surface roughness. Limit value of 6000 shocks and limitations of the research as well, was determined on the basis of previous experience in terms of time and material demandingness. If the indexable cutting inserts withstand this value, the experiment will be finished. Cutting insert will be described as satisfactory. Measurement is repeated three times. 
Formula for calculation the number of shocks:

$$
R=\frac{4 \cdot l}{f}
$$

$\mathrm{R}$ - number of shocks [-],

1 - machining length $[\mathrm{mm}]$,

$\mathrm{f}-$ feed per revolution $[\mathrm{mm}]$.

\section{Evaluation of Measurement}

We processed all measured values for all types of ceramic cutting inserts from Tungaloy Company that were tested. The results for all feeds are displayed in following diagram.

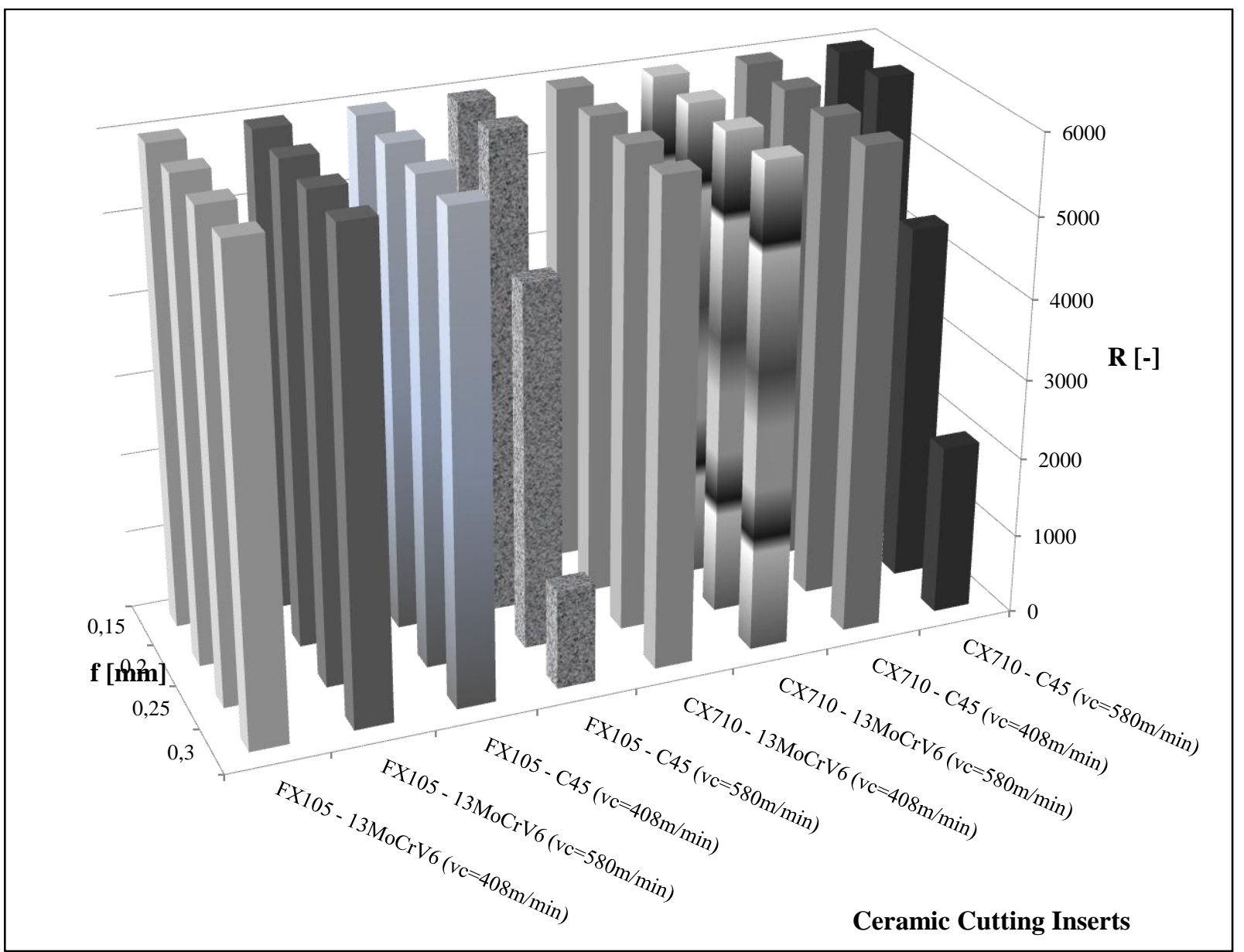

Fig. 2. Dependence - number of shocks on cutting speed for individual feeds

From the dependency graph of number of shocks on the cutting speed at 0,15 $\mathrm{mm}$ feed can be concluded that the number of shocks is maximal for all cutting inserts at $\mathrm{v}_{\mathrm{c}}=408 \mathrm{~m} / \mathrm{min}$ and $\mathrm{v}_{\mathrm{c}}=580 \mathrm{~m} / \mathrm{min}$. It concludes that these ceramic cutting inserts are suitable for interrupted cut at $0,15 \mathrm{~mm}$ feed.

From the dependency graph of number of shocks on the cutting speed at $0,2 \mathrm{~mm}$ feed can be concluded that the number of shocks is maximal for all cutting inserts at $\mathrm{v}_{\mathrm{c}}=408$ and $\mathrm{v}_{\mathrm{c}}=580 \mathrm{~m} / \mathrm{min}$ too. It concludes that these ceramic cutting inserts are 
suitable for interrupted cut at $0,2 \mathrm{~mm}$ feed. Both ceramic inserts achieved maximum number of shocks at lower feeds.

From the dependency graph of number of shocks on the cutting speed at 0,25 $\mathrm{mm}$ feed can be concluded that the number of shocks is the same for all cutting inserts and materials at lower cutting speed $\mathrm{v}_{\mathrm{c}}=408 \mathrm{~m} / \mathrm{min}$. Cutting inserts did not withstand the maximum number of shocks at both cutting speeds. Inserts withstood the maximum number of shocks only on $13 \mathrm{MoCrV} 6$ material at higher cutting speed. FX105 ceramic cutting inserts achieved the lowest number of shocks on C45 material - at higher cutting speed.

From the dependency graph of number of shocks on the cutting speed at $0,3 \mathrm{~mm}$ feed can be concluded that the number of shocks is the same for all ceramic cutting inserts and materials at $\mathrm{v}_{\mathrm{c}}=408 \mathrm{~m} / \mathrm{min}$ as in previous case. Cutting inserts withstood maximal number of shocks at higher cutting speed only on 13 MoCrV6 materials. FX105 ceramic cutting inserts achieved the lowest number of shocks on C45 material. The ability to withstand shocks decreases with increasing feed.

Through the centuries, producers of ceramic cutting tools have taken big steps forward. Properties have improved - their resistance to mechanical stress and tool wear, high temperature resistance, high accuracy. Some producers advise ceramic cutting inserts for interrupted machining at the present time.

\section{Conclusions}

Today's manufacturers are under intense competitive pressure. It is aim to produce higher quality parts at ever-faster production rates. A primary advantage of ceramic cutting tool inserts is the tremendous time savings they can offer. On the other hand the all cutting tool materials enjoy applications in which they excel and others in which their uses are limited.

In an increasing number of applications, the right tools for the works are ceramic inserts. It is a highly productive tool for milling and turning applications.

FX105 ceramic cutting inserts (13MoCrV6 material) reached the limit number of shocks at both cutting speeds and feeds of all. It means, that they have a high resistance and ability to perform interrupted cut in this material.

FX105 ceramic cutting inserts (C45 material) reached the limit value at lower cutting speed for all feeds. The cutting inserts withstand fewer number of shocks when cutting speed is $\mathrm{v}_{\mathrm{c}}=580 \mathrm{~m} / \mathrm{min}$ and with increasing feed of cutting insert. The number of shocks decreases with increasing value of the feed. FX105 ceramic cutting inserts were able to withstand the limit value of 6000 shocks at $0,15 \mathrm{~mm}$ and $0,2 \mathrm{~mm}$.

CX710 ceramic cutting inserts (13MoCrV6 material) reached the limit number of shocks at both cutting speeds and feeds of all. That means they have a high resistance and ability to perform interrupted cut in this material. This material have higher of toughness and heat conductivity than FX105.

CX710 ceramic cutting inserts (C45 material) reached the limit value at lower cutting speed for all feeds. The cutting inserts withstand fewer number of shocks when cutting speed is $\mathrm{v}_{\mathrm{c}}=580 \mathrm{~m} / \mathrm{min}$ and with increasing feed of cutting insert - like in previous case for the $\mathrm{C} 45$ material. The number of shocks decreases with 
increasing value of the feed. CX710 ceramic cutting inserts were able to withstand the limit value of 6000 shocks at $0,15 \mathrm{~mm}$ and $0,2 \mathrm{~mm}$.

These tests showed that FX105 and CX710 ceramic cutting inserts can be used for interrupted cut. Both cutting inserts withstood maximum number of shocks at $13 \mathrm{MoCrV} 6$ material (at lower or higher cutting speed). It means, that FX105 and CX710 inserts have a high resistance and ability to perform an interrupted cut at $13 \mathrm{MoCrV} 6$ material.

The next steps in research plan will be found out the effect of thermal and mechanical shock and tool-life at unbalanced preparation. The gap between slats will not be constant. The thermal and mechanical shock leads to cracking or fracture. Excellent thermal and mechanical shock resistance is required for satisfactory performance of an insert in the all operation.

\section{Acknowledgements}

This paper was supported by the Czech Science Foundation, grant number 101/08/P118, entitled Ceramic Cutting Tool Tests at Interrupted Cut.

\section{References}

Cep, R. (2010). Design and verification of testing methodology for cutting tools at interrupted cut. Habilitation thesis. VŠB - Technical University of Ostrava, 119 p., Ostrava

Cep, R.; Neslusan, M. \& Barisic, B. (2008). Chip Formation Analysis During Hard Turning. Strojarstvo, vol 50, No. 6, pp. 337 - 345. ISSN 0562 - 1887, Zagreb

Dobransky, J. \& Hatala, M. (2007). Influence of selected technological parameter to quality parameters by injection moulding. In Annals of DAAAM for 2007 \& proceedings of the 18th International DAAAM Symposium: Intelligent Manufacturing \& Automation: Focus on Creativity, Responsibility, and Ethics of Engineers: 24-27th October 2007, Vienna: DAAAM International, 2007. 2 p. ISBN 3-901509-58-5, Zadar, Croatia

Jurko, J.; Panda, A. \& Gajdoš, M. (2009). Accompanying phenomena in the cutting zone machinability during turning of stainless steels. International Journal Machining and Machinability of Materials, vol 5, No. 4, pp. 383-400. ISSN 1748-5711(print), ISSN 1748-572X (online)

Reiner, J. (2009). Testing of ceramic cutting inserts by interrupted cutting simulator. Diploma thesis. VS̆B - Technical University of Ostrava, 73 p., Ostrava

Amin, A. K. M. (2011) Comparison of machinability of ceramic insert in room temperature and cryogenic cooling conditions during end milling inconel 718. Advanced Machining Towards Improved Machinability of Difficult-to-Cut Materials. IIUM Press, Kuala Lumpur, Malaysia, pp. 209-215. ISBN 9789674181758

*** (2007) http://www.insmetal.net/ - Standard ISO 3685: 1990 - Tool Life Testing with Single Cutting Tools. Tungaloy Catalogue: Cutting Tools [online], (2007). Accessed on: 2011-02-13 